\title{
Experimental Study on Bond-Strengthening Hooks for RC Beams
}

\author{
Yuichi Sato ${ }^{1}$, Katsuhiro Nagatomo ${ }^{2}$ and Yoshifumi Nakamura ${ }^{3}$
}

Received 6 November 2008, accepted 29 March 2009

\begin{abstract}
This paper presents an experimental investigation of bond-strengthening hooks as a new method to increase bond strength along flexural reinforcing bars in reinforced concrete $(\mathrm{RC})$ beams. The proposed method attempts to increase confining stiffness around the flexural bars by placing U-shaped hooks and to prevent premature bond splitting failure. Ten specimens with different numbers and sizes of hooks were prepared to verify the strengthening effectiveness under monotonic four-point loading. The test results indicated that the hooks increased the bond strength along flexural bars although the strengthening effectiveness was limited by the effective number of anchors of hooks $N_{\text {be. }}$ This limit is determined by the size of the stress-transmitting zones of the concrete around the anchors of the hooks. The bond-strengthening effectiveness of hooks was found to be equivalent to that of conventional internal ties.
\end{abstract}

\section{Introduction}

The shear capacity of reinforced columns and beams is increased by (1) increasing the amount of shear reinforcement, and (2) increasing the strength of shear reinforcement. The former approach often causes congestion due to overreinforcement, while the latter one may degrade the bond strength between the longitudinal bars and concrete (AIJ 1999). From the viewpoint of the truss mechanism model, bond failure can occur due to the diagonal truss strut force, which is increased with increasing both the value of $p_{w}$ and the yield stress $\sigma_{\mathrm{w}}$ of shear reinforcement. On the other hand, the bond strength along the longitudinal bars, which is expected to resist the truss action, depends only on the value of $p_{w}$.

Hence, the authors have proposed an alternative, the bond strengthening hook, which is a supplemental bar applied along the longitudinal bars to increase the bond strength (Nagatomo et al. 2003; Hosokawa et al. 2003; Sato et al. 2003; Sato et al. 2006). The proposed bars are U-shaped, avoiding a closed form for easy arrangement. The authors' previous tests showed a considerable improvement of the bond strength due to the use of the hooks. Equations have been proposed to estimate the bond strength along longitudinal bars and the shear strength of RC members with hooks based on the Design Guidelines for Earthquake Resistant Reinforced Concrete Buildings Based on Inelastic Displacement Concept, Architectural Institute of Japan (AIJ).

In these studies, however, the bond strengths were estimated as an average along the member and sufficient attention was not paid to the distribution of bond splitting cracks and bond stresses. Further, the variations of ex-

\footnotetext{
${ }^{1}$ Assistant Prof., Dept. of Urban and Environmental Engineering, Kyoto University, Kyoto, Japan. E-mail:satou@archi.kyoto-u.ac.jp

${ }^{2}$ Mitoyo-sangyo Corporation, Kagawa, Japan.

${ }^{3}$ Neturen Corporation, Tokyo, Japan.
}

perimental parameters (i.e., shear reinforcement ratio, ratio of net concrete width to total diameter of longitudinal bars, ratio of number of hooks in a cross-section to number of longitudinal bars, etc.) were limited due to test plan limitations.

This study aims at an examination of the previously proposed bond strength equation (Sato 2003) through a series of loading tests of RC beams, which contain varied spacings and numbers of bond strengthening hooks. In these tests, stirrups made of mild steel were used instead of high-strength steels in order to observe the behaviors of RC members under basic reinforcing conditions.

\section{Tests}

Figure 1 shows the geometry and bar arrangement of the specimens. The specimens were RC beams of 350 $\mathrm{mm}$ height and 2,000 mm length and were subjected to four-point loadings. Three longitudinal bars of $19.1 \mathrm{~mm}$ diameter were placed on the compression (upper) side. On the other hand, three $19.1 \mathrm{~mm}$ diameter bars were placed in the tension (lower) side of specimens No. 2 and No. 6, four bars for No. 1, No. 3, No. 4, and No. 5, and five bars for No. 7, No. 8, No. 9, and No. 10. The specimens contained shear reinforcing stirrups and bond strengthening hooks of $6.35 \mathrm{~mm}$ diameter with varied spacings. Figure 2 shows a detailed view of the hooks. The locations of the hooks are indicated by a dotted rectangle in Fig. 1. The two ends of the stirrup were overlapped and welded together over a length equal to ten times the bar diameter. The size of the cross-section and the number of stirrups and hooks were determined so as to induce bond splitting cracks along the longitudinal bars. Additional stirrups of $6.35 \mathrm{~mm}$ diameter were provided through the development length of the longitudinal bars to induce bond splitting cracks before the shear failure.

The experimental parameters were the width of the beam $(200 \mathrm{~mm}$ and $250 \mathrm{~mm})$, the number of longitudinal bars (three, four, and five), the spacing of stirrups $\left(s_{\mathrm{W}}=\right.$ 


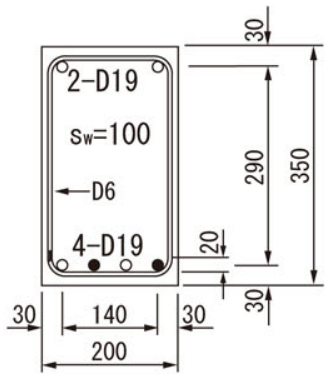

(a) №. 1

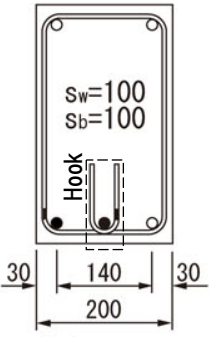

(b) No. 2

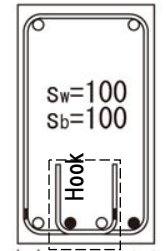

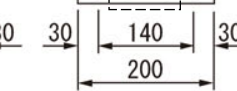

(c) No. 3

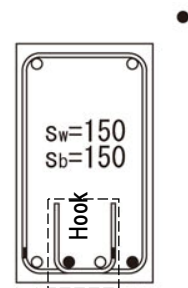

- : Bar with gauges

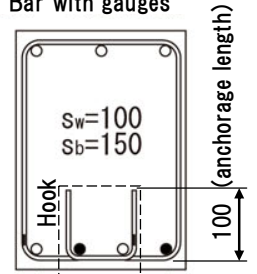

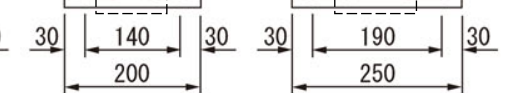

(d) No. 4

(e) No. 5

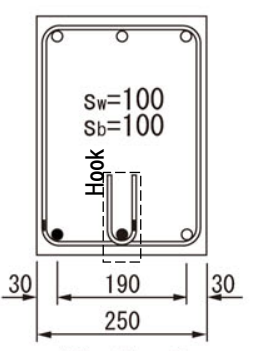

(f) No. 6

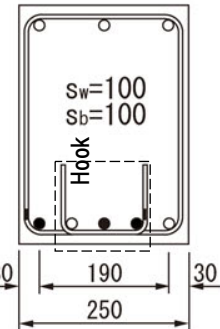

(g) No. 7

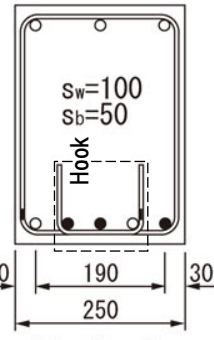

(h) No. 8

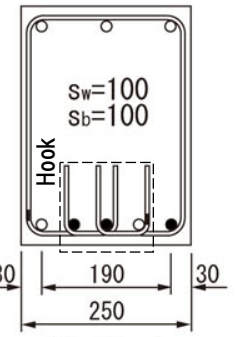

(i) No. 9

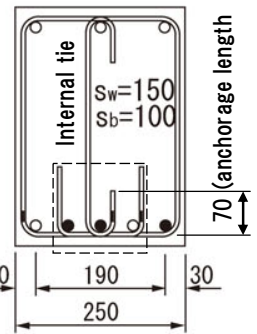

(j) No. 10

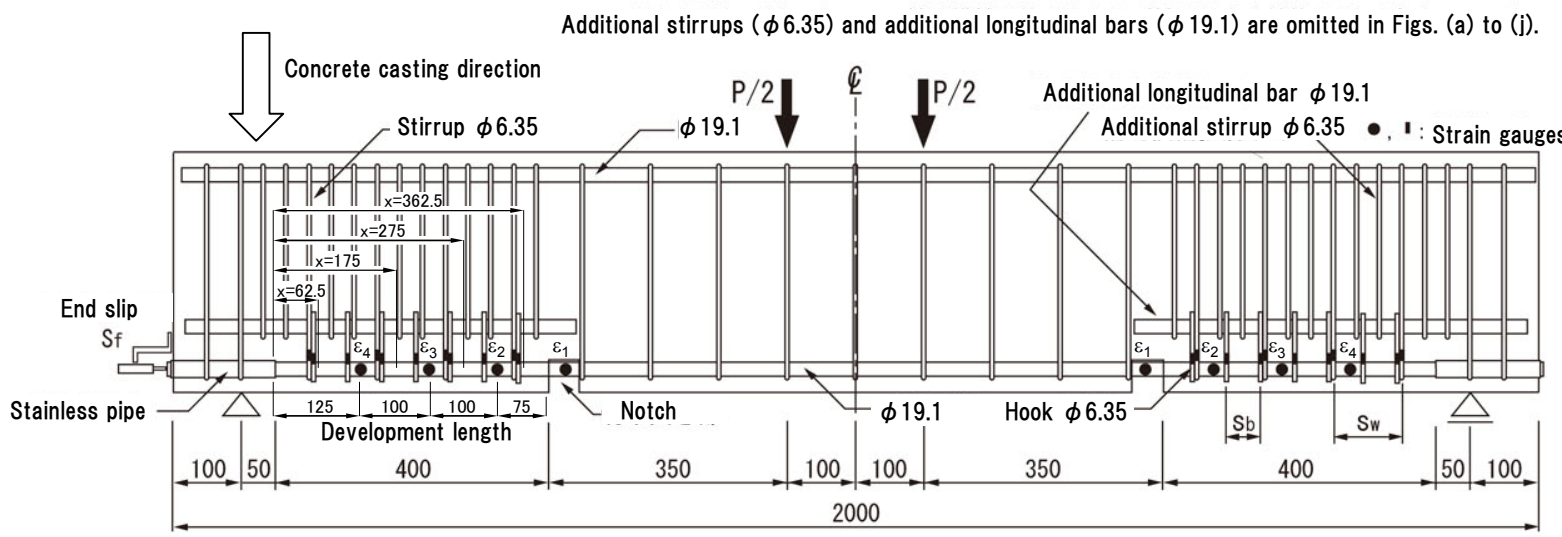

(k) Lateral elevation (№. 8)

Fig. 1 Configurations of specimens.

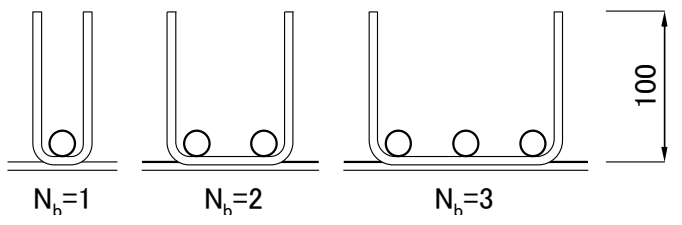

Fig. 2 Bond strengthening hook.

$100 \mathrm{~mm}$ and $150 \mathrm{~mm})$, the spacing of hooks $\left(s_{\mathrm{b}}=50 \mathrm{~mm}\right.$, $100 \mathrm{~mm}$ and $150 \mathrm{~mm}$ ), and the width of hooks (i.e. spacing between two anchorages of a hook). The hooks were either overlapped on the stirrup or placed between adjacent stirrups.

The ends of the lower longitudinal bars were covered with stainless pipes while a notch was made at the inside end of the shear span to keep the development length within $400 \mathrm{~mm}$. This length was determined based on the observation in a previous study (Fujii et al. 1981) that the bond strength was not affected as long as the development length was more than 20 times the bar diameter. The depth of the bond strengthening hook was $100 \mathrm{~mm}$ (Fig. 2), which was determined based on (1) the depth of the bond splitting failure region observed in several previous tests (Nagatomo et al. 2003; Hosokawa et al. 2003; and Tanaka et al. 2004), and (2) the AIJ standard requiring the anchorage length of a bended bar to be 12 times the bar diameter (AIJ 1986).

Table 1 lists properties of the steel bars. The yield stress of the lower (tension) longitudinal bar was 431.4 MPa while that of the stirrups and hooks was $390.5 \mathrm{MPa}$. The bending radius of the corners of the stirrups and hooks was $20 \mathrm{~mm}$. The hooks were not applied along the central constant moment region since bond splitting would not be induced along this region. Compressive concrete strengths were 29.0 MPa for specimens No. 2, No. 3, No. 6 and No. 7, $24.8 \mathrm{MPa}$ for No. 1, No. 4, No. 5, No. 9 and No. 10, and 21.3 MPa for No. 8. The concretes were mixed with air-entraining agents resulting in a 
slump of $18 \mathrm{~cm}$. The maximum aggregate size was 20 $\mathrm{mm}$. The casting direction is indicated in Fig. 1

Specimens No. 1, No. 2, No. 4, No. 6, and No. 8 were subjected to monotonic loads by a hydraulic servo-pulse actuator. The loading was stopped when either side of the specimen failed. After the load was removed, the failed region was strengthened by confining it with steel plates of $20 \mathrm{~mm}$ thickness and prestressing bolts. Then the specimen was reloaded until the other side failed.

For specimens No. 3, No. 5, No. 7, No. 9, and No. 10, constant loads of $300 \mathrm{kN}$ were repeated five times to deteriorate the specimens under a limit actuator's capacity. Specimen No. 3 failed by shear after the repeated loads but specimens No. 5 and No. 7 did not fail. For specimens No. 9 and No. 10, the actuator was replaced by a larger one after the repeated loads and reloaded. Table 2 shows the loading hysteresis of each specimen.

Load $\mathrm{P}$, central deflection $\delta$, the strains of the lower longitudinal bars, stirrups, and hooks, and the end slips of the longitudinal bars were measured. Figure 1 indicates the longitudinal bars, to which strain gauges were applied at $100 \mathrm{~mm}$ spacings. The end slips of the longitudinal bars were measured by displacement transducers. Strain gauges were also applied on all the stirrups and hooks along the development length.

Double water-proof coatings were provided for the strain gauges applied on the bars (Fig. 3). The coating length $(25 \mathrm{~mm})$ was subtracted when the bond stresses were calculated.

\section{Equations for bond strength estimation}

\subsection{AlJ Guidelines (AlJ 1999)}

The Design Guidelines for Earthquake Resistant Reinforced Concrete Buildings Based on Inelastic Dis-

Table 1 Properties of steel bars.

\begin{tabular}{|c|c|c|c|}
\hline & \multicolumn{2}{|c|}{ Longitudinal bar } & $\begin{array}{c}\text { Stirrup and } \\
\text { bond } \\
\text { strengthening } \\
\text { hook }\end{array}$ \\
\cline { 2 - 3 } & lower & upper & 6.35 \\
\hline $\begin{array}{c}\text { Diameter } d_{\mathrm{b}} \\
(\mathrm{mm})\end{array}$ & 19.1 & 19.1 & 390.5 \\
\hline $\begin{array}{c}\text { Yield stress } f_{\mathrm{y}} \\
(\mathrm{MPa})\end{array}$ & 431.4 & 461.0 & 589.4 \\
\hline $\begin{array}{c}\text { Tensile strength } \\
f_{\mathrm{u}}(\mathrm{MPa})\end{array}$ & 640.5 & 555.0 & 202.0 \\
\hline $\begin{array}{c}\text { Elastic modulus } \\
E_{\mathrm{s}}(\mathrm{GPa})\end{array}$ & 192.1 & 186.0 & 2000 \\
\hline
\end{tabular}

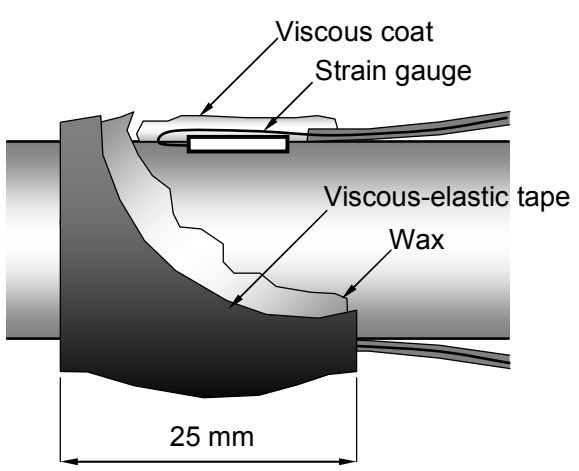

Fig. 3 Coating of strain gauge.

placement Concept, AIJ (1999), estimates bond strength $\tau_{\text {ucal }}$ along longitudinal bars as the sum of the contributions of concrete and lateral reinforcements (i.e. stirrups or hoops):

$$
\tau_{\text {ucal }}=\alpha_{\mathrm{t}}\left\{\left(0.086 b_{\mathrm{si}}+0.11\right) \sqrt{f_{c}^{\prime}}+k_{\mathrm{st}}\right\}
$$

where

$$
\begin{aligned}
k_{\mathrm{st}} & =\text { contribution of stirrups } \\
& =\left(56+47 N_{\mathrm{w}} / N_{1}\right)\left(b_{\mathrm{si}}+1\right) p_{\mathrm{w}}
\end{aligned}
$$

$b_{\mathrm{si}}=$ ratio of net concrete width to total diameter of longitudinal bars;

$$
=\left(b-N_{1} d_{\mathrm{b}}\right) /\left(N_{1} d_{\mathrm{b}}\right)
$$

$p_{\mathrm{w}}=$ cross sectional area ratio of stirrups or hoops;

$$
=a_{\mathrm{w}} /\left(b_{\mathrm{e}} s_{\mathrm{w}}\right)
$$

$\alpha_{\mathrm{t}}=0.75+f^{\prime}{ }_{\mathrm{c}} / 400$ for bars in upper side of beam;

$$
=1 \quad \text { for bars in other place }
$$

$a_{\mathrm{w}}=$ total cross sectional area of stirrups or hoops in the same plane $\left(\mathrm{mm}^{2}\right)$;

$b$ = width of beam or column (mm);

$b_{\mathrm{e}}=$ effective width of beam or column ( $\left.\mathrm{mm}\right)$;

$d_{\mathrm{b}}=$ diameter of longitudinal bar (mm);

$N_{1}=$ number of longitudinal bars;

$N_{\mathrm{w}}=$ number of anchorages of stirrups, internal ties or hoops in the same plane; and

$S_{\mathrm{W}}=$ spacing of adjacent stirrups or hoops (mm).

The ratio $N_{\mathrm{w}} / N_{1}$ is one of the indices of confining effect per longitudinal bar, which was proposed by Fujii et al. (1981). The AIJ guidelines classify the bond failure into two modes: (1) The side splitting mode in which the

Table2 Loading hysteresis.

\begin{tabular}{|c|l|}
\hline Specimen & Hysteresis \\
\hline Nos. 1, 2, 4, 6, and 8 & Load $\rightarrow$ One side failed $\rightarrow$ Reload $\rightarrow$ Another side failed \\
\hline Nos. 3, 5, and 7 & Load $\rightarrow$ One side failed $\rightarrow$ Reload $\rightarrow 300 \mathrm{kN}$ x 5 times \\
\hline Nos. 9 and 10 & $\begin{array}{l}\text { Load } \rightarrow 300 \mathrm{kN} \text { x } 5 \text { times } \rightarrow \text { Replacement of jack } \rightarrow \text { Reload } \rightarrow \text { One side failed } \rightarrow \text { Reload } \\
\rightarrow \text { Another side failed }\end{array}$ \\
\hline
\end{tabular}


splitting cracks are horizontally induced, and (2) the corner splitting mode in which the corner cover concrete is diagonally split along the corner longitudinal bars. Equations (1) to (5) are available only for the former mode.

\subsection{Proposed equation}

The authors propose the modified equations to extend the AIJ guidelines to members with bond strengthening hooks (Sato 2003).

$$
k_{\mathrm{st}}=\left\{56+47\left(N_{\mathrm{w}}+N_{\mathrm{be}}\right) / N_{1}\right\}\left(b_{\mathrm{si}}+1\right)\left(p_{\mathrm{w}}+p_{\mathrm{be}}\right)
$$

where

$p_{\text {be }}=$ effective cross sectional area ratio of hooks;

$$
=N_{\mathrm{be}} a_{\mathrm{b}} /\left(b_{\mathrm{e}} s_{\mathrm{b}}\right)
$$

$a_{\mathrm{b}}=$ cross sectional area of an anchorages of hook

$\left(\mathrm{mm}^{2}\right)$;

$N_{\text {be }}=$ effective number of anchorages of hooks in the

same plane; and

$s_{\mathrm{b}}=$ spacing of adjacent hooks $(\mathrm{mm})$.

The number of anchorages of hooks in the same plane had been varied from two up to eight in the previous test (Nagatomo et al. 2003; Hosokawa et al. 2003; Sato et al. 2003; and Sato et al. 2006). The test results showed that there was an upper limit of the bond strengthening ef-

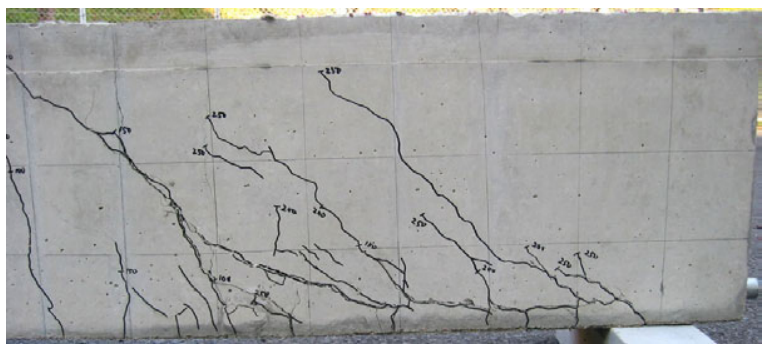

(a) Specimen No. 2 fectiveness of hooks. Hence, effective number $N_{\text {be }}$ was introduced instead of net number $N_{\mathrm{b}}$ to take into account the limit of strengthening effectiveness.

$$
N_{\mathrm{be}}=\min \left[N_{\mathrm{b}}, b_{\mathrm{e}} /\left(15 d_{\mathrm{bb}}\right)\right]
$$

where $d_{\mathrm{bb}}=$ diameter of bond strengthening hook. Equation (8) was developed in accordance with CEB-FIP model code (CEB-FIP 1978), which suggests that a reinforcing bar induces stress to a concrete zone within 15 bar diameters $d_{\mathrm{bb}}$ from the reinforcement (Sato 2003). The following sections discuss these equations in detail.

\section{Test results}

\subsection{Failure mode}

Figures 4(a) and (b) show the final crack patterns of specimens No. 2 and No. 10, respectively. First, discrete flexural cracks occurred along the development length. Next, a diagonal crack was initiated from the notch and then from the region along the development length. Then, small diagonal bond splitting cracks appeared along the longitudinal bars, which finally interconnected and resulted in the final failure mode. The bond splitting cracks usually initiated from the region near the notch and then occurred in the end region. These splitting cracks, however, did not always continuously proceed. Figure 5 shows relationships between the load and central deflection. No yielding was observed along the longitudinal bars.

\subsection{Experimental bond strengths}

Table 3 lists the experimental parameters and bond

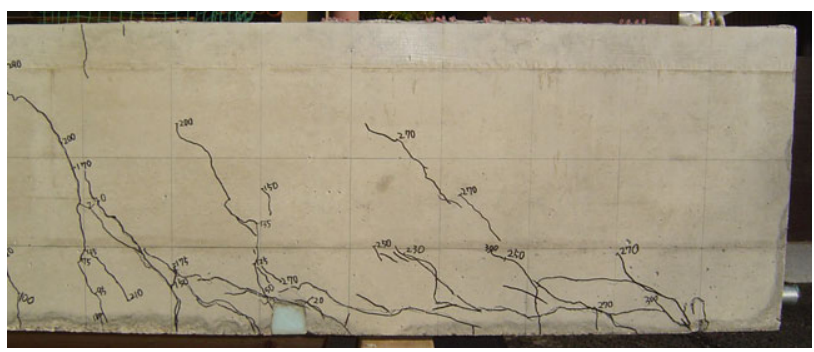

(b) Specimen No. 10

Fig. 4 Final crack pattern.

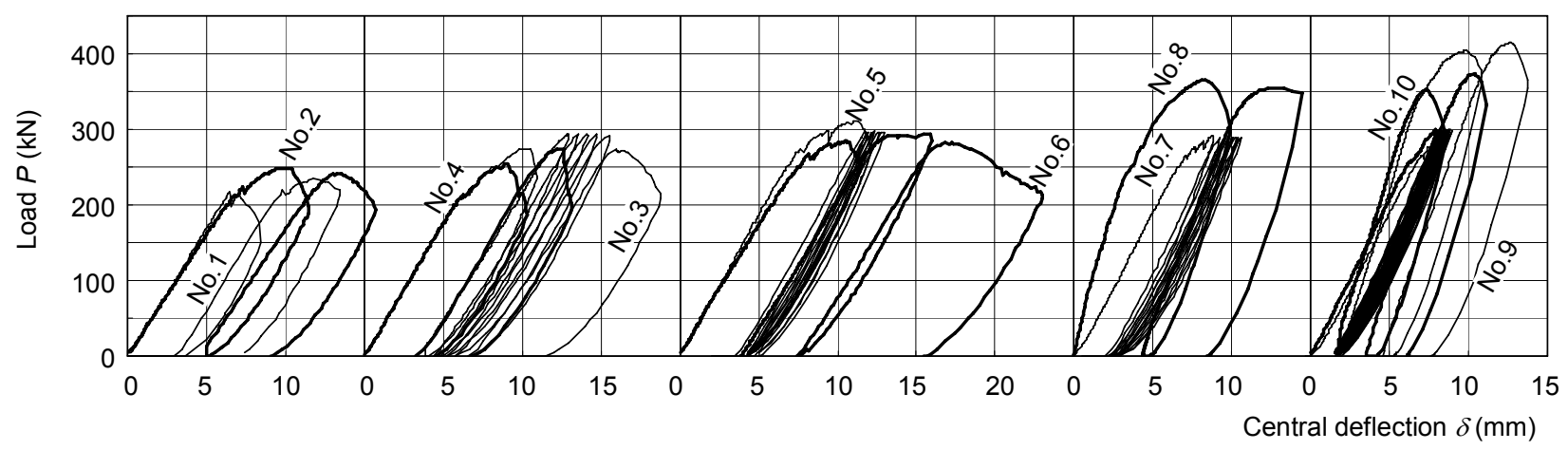

Fig.5 Relationship between load and central deflection. 
Table 3 Experimental parameters and bond strengths.

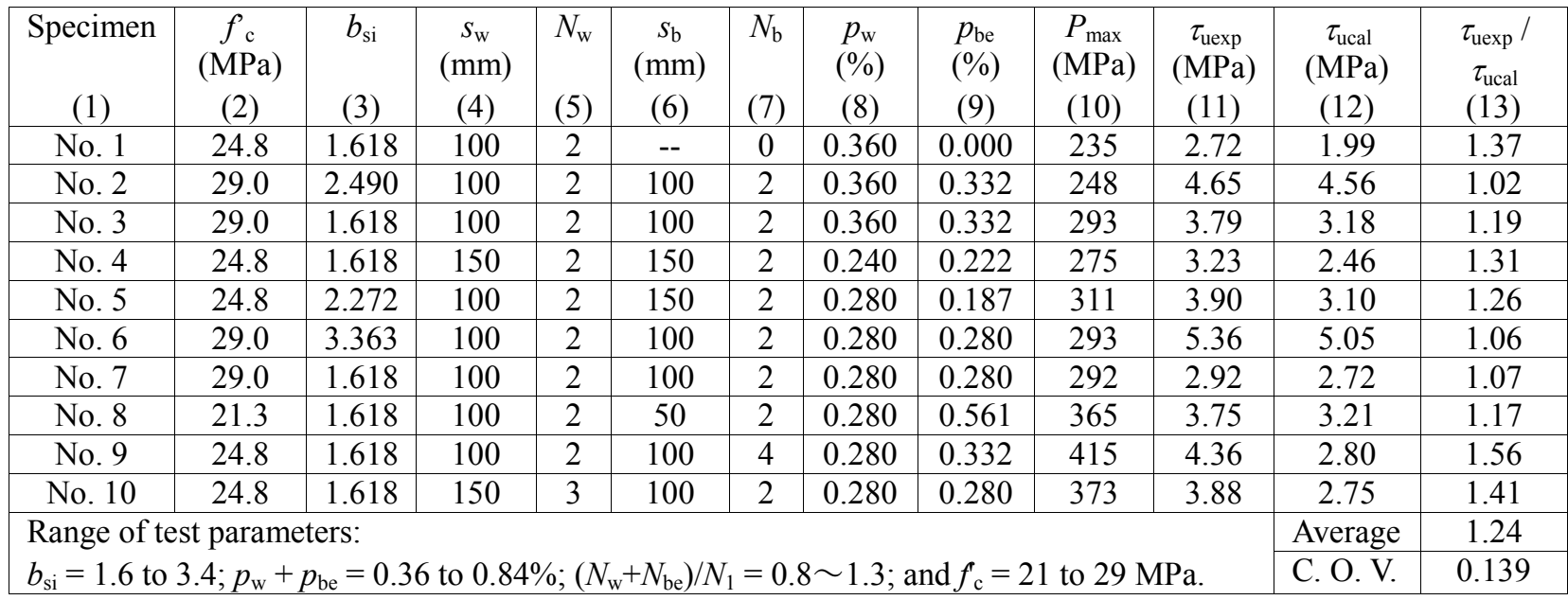

strengths. The experimental bond stresses were calculated based on the measured strains along the longitudinal bars.

Figures 6 to 8 show relationships between bond strengths $\tau_{\text {uexp }}$ and three experimental parameters used in Eq. (6). Bond strengths $\tau_{\text {uexp }}$ were normalized through division by the square root of compressive concrete strength $f^{\prime}$ in $\mathrm{MPa}$.

Figure 6 shows the relationship between $\tau_{\text {uexp }} / \sqrt{f_{c}^{\prime}}$ and the ratio of net concrete width to the total diameter of the longitudinal bars $b_{\mathrm{si}}$. The values in parentheses indicate $\left(N_{\mathrm{w}}+N_{\mathrm{be}}\right) / N_{\mathrm{l}}$. The values of $\tau_{\text {uexp }} / \sqrt{f_{c}^{\prime}}$ increase as $b_{\mathrm{si}}$ increases for all three values of total cross sectional area ratios of the stirrups and hooks $p_{\mathrm{w}}+p_{\text {be }}$. On the other hand, the relationship between $\tau_{\text {uexp }} / \sqrt{f_{c}^{\prime}}$ and $p_{\mathrm{w}}$ $+p_{\text {be }}$ cannot be discussed because the values of $\left(N_{\mathrm{w}}+\right.$ $N_{\text {be }} / / N_{1}$ vary.

Figure 7 shows the relationship between $\tau_{\text {uexp }} / \sqrt{f_{c}^{\prime}}$ and the ratio of number of anchorages of the stirrups and the hooks to the number of longitudinal bars $\left(N_{\mathrm{w}}+N_{\mathrm{be}}\right) /$ $N_{1}$. The values in parentheses indicate $b_{\mathrm{si}}$. The values of $\tau_{\text {uexp }} / \sqrt{f_{c}^{\prime}}$ increase as $\left(N_{\mathrm{w}}+N_{\text {be }}\right) / N_{1}$ increases for both values of $p_{\mathrm{w}}+p_{\mathrm{be}}$.

Figure 8 shows the relationship between $\tau_{\text {uexp }} / \sqrt{f_{c}^{\prime}}$ and $p_{\mathrm{w}}+p_{\mathrm{be}}$. The values of $\tau_{\text {uexp }} / \sqrt{f_{c}^{\prime}}$ increase as the value of $p_{\mathrm{w}}+p_{\text {be }}$ increases for both values of $\left(N_{\mathrm{w}}+N_{\mathrm{be}}\right) /$ $N_{1}$. The values of $\tau_{\text {uexp }} / \sqrt{f_{c}^{\prime}}$ become larger as the value of $\left(N_{\mathrm{w}}+N_{\mathrm{be}}\right) / N_{1}$ increases when $p_{\mathrm{w}}+p_{\text {be }}$ is the same.

The above empirical tendencies between $\tau_{\text {uexp }} / \sqrt{f_{c}^{\prime}}$ and the three parameters $b_{\mathrm{si}},\left(N_{\mathrm{w}}+N_{\mathrm{be}}\right) / N_{1}$, and $p_{\mathrm{w}}+p_{\text {be }}$ agree with Eq. (6) even when bond strengthening hooks are added.

\subsection{Bond strength estimation}

Figure 9 shows the relationship between experimental bond strengths $\tau_{\text {uexp }}$ and bond strengths $\tau_{\text {ucal }}$ calculated by Eq. (6) (see 11th and 12th columns in Table 3). The $\tau_{\text {uexp }}$ $/ \tau_{\text {ucal }}$ ratio exceeds 1.0 for all the specimens. The average of $\tau_{\text {uexp }} / \tau_{\text {ucal }}$ is 1.24 and the coefficient of variation

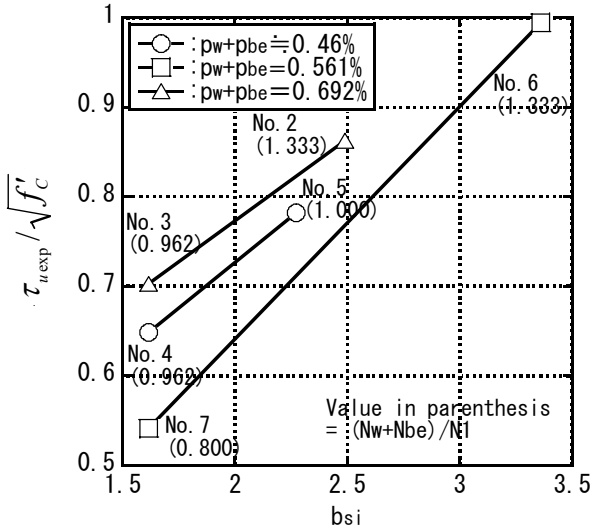

Fig. 6 Relationship between bond strength and $b_{\text {si }}$.

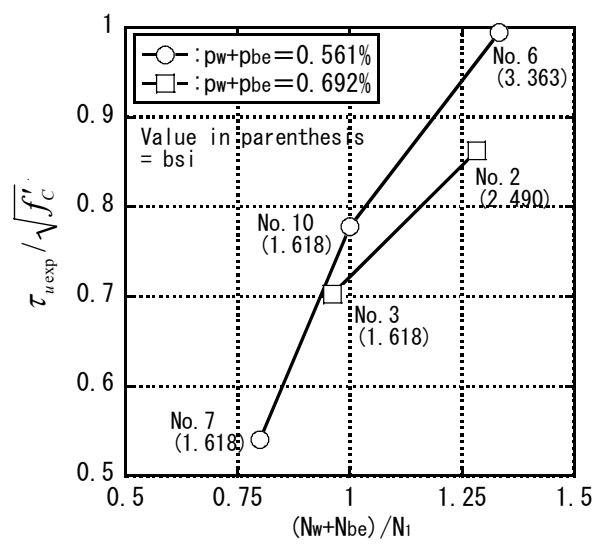

Fig. 7 Relationship between bond strength and $\left(N_{\mathrm{w}}+\right.$ $\left.N_{\text {be }}\right) / N_{1}$.

(C.O.V.) is 0.139 . The C.O.V. is 0.114 when $N_{\mathrm{b}}$ is used instead of $N_{\text {be }}$, so substitution of $N_{\text {be }}$ did not always improve the bond strength estimation. However, it is recommended to use $N_{\text {be }}$ because the authors' previous study 


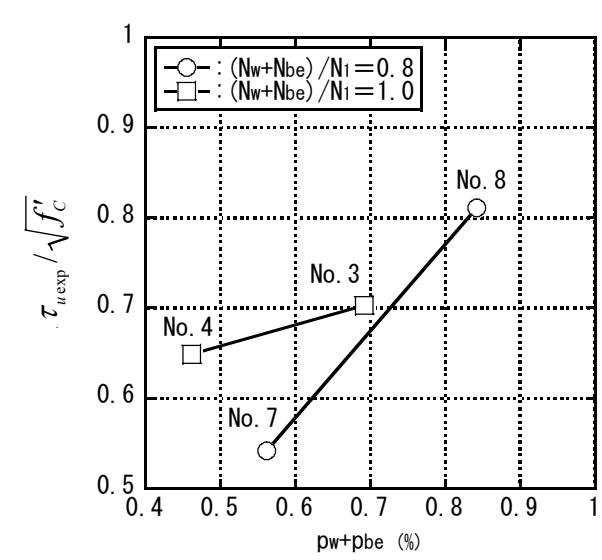

Fig. 8 Relationship between bond strength and $p_{\mathrm{w}}+p_{\mathrm{be}}$.

indicated that $N_{\mathrm{b}}$ often results in unsafe strength estimation.

Equation (6) is available within ranges of $b_{\mathrm{si}}=1.6$ to $3.4, p_{\mathrm{w}}+p_{\text {be }}=0.36$ to $0.84 \%,\left(N_{\mathrm{w}}+N_{\text {be }}\right) / N_{1}=0.8$ to 1.3 , and $f_{\mathrm{c}}^{\prime}=21$ to $29 \mathrm{MPa}$. The ratios $\tau_{\text {uexp }} / \tau_{\text {ucal }}$ of specimens No. 9 and No. 10 are considerably large. For specimen No. 10, the internal ties are supposed to confine the longitudinal bars and result in higher bond strength. The influence of the internal ties is discussed in the following section.

\section{Miscellaneous behaviors of specimens}

\subsection{Local bond stress-slip relationship}

Figures 10(a) and 10(b) show the relationships between local bond stress $\tau$ and slip S of two longitudinal bars in specimen No. 1. Each figure presents the bond stress-slip curves of four points at a bar. The slips are calculated as a summation of end slip $\mathrm{S}_{\mathrm{f}}$ and the bar elongation, which is derived from integration of the measured bar strains. The symbol $\mathrm{x}$ denotes the distance from the unbonded part (see Fig. 1(K)).

Figure 10(a) represents the bar that touches the horizontal parts of the stirrups while Fig. 10(b) shows the bar that touches the corner of the stirrups. The bond stresses of the latter became larger because of the con-

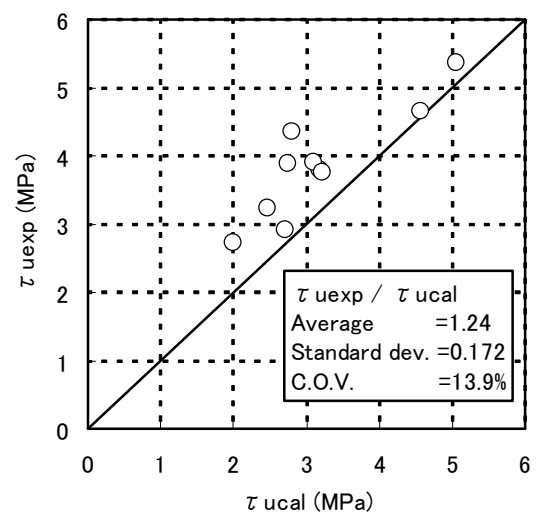

Fig. 9 Relationship between experimental and calculated bond strengths.

fining effect at the corner of the stirrups.

The bond stress-slip curves were almost identical when the slips were less than $0.05 \mathrm{~mm}$. After the bond splitting cracks occurred, the slips considerably increased and differed. The differences between the measured points are supposed to depend on the progress of bond splitting cracks.

Figure 10(c) shows the bond stress-slip relationships at four points along the longitudinal bars in specimen No. 3. The bar touches the bond strengthening hooks. As mentioned above, loading of specimen No. 3 was repeated five times. The bond stresses were not constant even in the repetitions of constant load P as Fig. 10(c) shows. Negative bond stresses were observed at $\mathrm{x}=$ $362.5 \mathrm{~mm}$ for a slip larger than $0.7 \mathrm{~mm}$ since residual slips exist at zero loads.

\subsection{Distribution of bond stress}

Figure 11 shows the distributions of bond stress $\tau$ along the longitudinal bar in specimen No. 2, which touches the corner of the hooks. Similar distributions are observed in the nine other specimens.

In general, the bond stress distributions become flatter as load $\mathrm{P}$ increases because of the progress of bond splitting cracks. The bond stresses near the notches, however, are usually small because large bond splitting

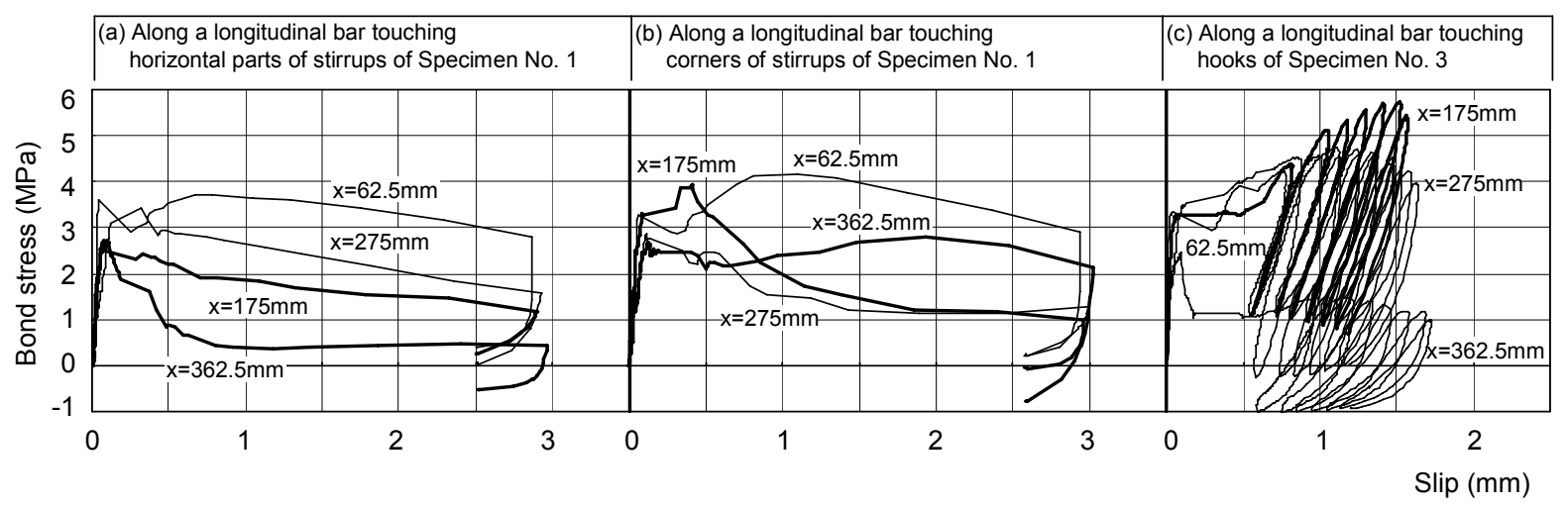

Fig. 10 Typical relationship between local bond stress $\tau$ and slip S. 
cracks occurred in this region. The length of the bond deterioration regions was four to five times the longitudinal bar diameter.

\subsection{Stresses of bond strengthening hook $\sigma_{\mathrm{b}}$}

Figure 12(a) shows the distributions of stresses of bond strengthening hooks $\sigma_{\mathrm{b}}$ in specimen No. 2. The stresses are derived from the strain gauges attached at a depth of $25 \mathrm{~mm}$ from the horizontal part of the hook. The hook yielded at $\mathrm{x}=150 \mathrm{~mm}$, where local bending occurred due to a large splitting crack. This yielding of the hook was limited locally and did not reduce the bond stress of the longitudinal bar at $\mathrm{x}=150 \mathrm{~mm}$, as shown in Fig. 11 .

Figure 12(b) shows the hook stress distributions of specimen No. 3. The distribution forms an ascending parabolic curve at a lower value of load $\mathrm{P}$, and then becomes flatter as the load increases. The maximum stress is around $200 \mathrm{MPa}$, which indicates that normal mild steel is satisfactory as the material of the bond strengthening hook.

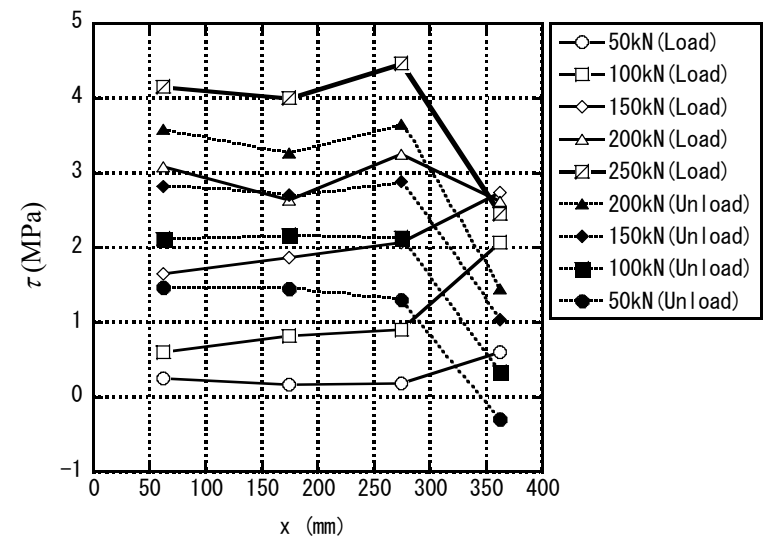

Fig. 11 Typical bond stress distributions (Specimen No. 2).

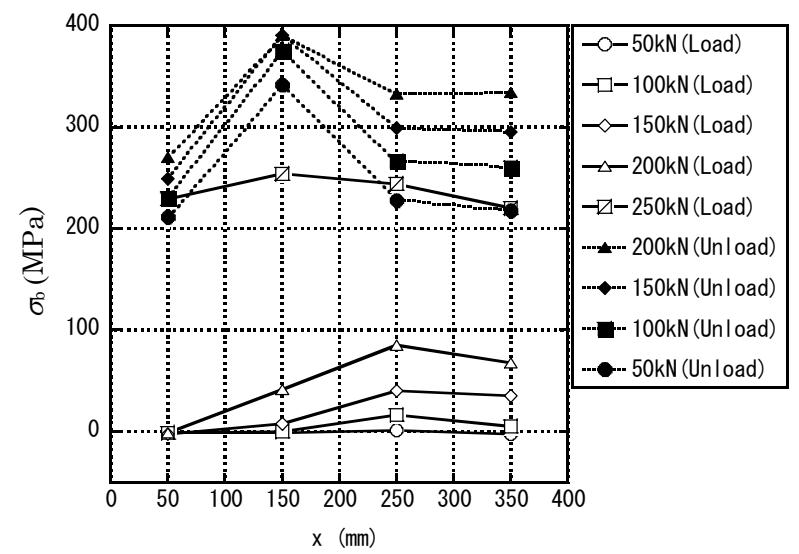

(a) Specimen No. 2

\subsection{Stresses of stirrups and internal ties $\sigma_{\mathrm{w}}$}

Figure 13(a) shows the distributions of stirrup stresses $\sigma_{\mathrm{w}}$ of specimen No. 2. The stresses are derived from the strain gauges attached at a depth of $25 \mathrm{~mm}$ from the horizontal part of the stirrup. The stirrup stresses drastically increase when the value of load P exceeds $200 \mathrm{kN}$, a level at which the bond splitting cracks progress. In specimen No. 2, however, the maximum hook stress is $350 \mathrm{MPa}$, which is lower than the yield stress.

On the other hand, yielding of the stirrup is observed in specimen No. 5 as typically shown in Fig. 13(b). Yielding of the stirrups are also observed in other specimens, although the specimens contained additional reinforcements to resist shear cracks. Hence, high-strength steel reinforcements may be preferable even when the longitudinal bars are strengthened with bond strengthening hooks.

Figure 14 shows the distributions of internal tie stresses of specimen No. 10. The stresses are derived from the strain gauges attached at a depth of $25 \mathrm{~mm}$ from the bottommost point of the internal tie. The anchorage depth of the tie is $70 \mathrm{~mm}$. This depth, which is smaller than that of the bond strengthening hook, was determined considering the bar arranging work.

Figure 14(a) shows the distributions in the span that failed at first while Fig. 14(b) those in another span that failed later. In the span shown in Fig. 14(a), bond splitting failure occurs and two of the three ties yield. The ties in another span shown in Fig. 14(b) restrained crack opening although the tensile stresses were lower than 250 $\mathrm{MPa}$. From the viewpoint of bar arranging work, however, internal ties are obviously less advantageous than hooks.

\section{Conclusions}

This paper presents an experimental study of reinforced concrete beams that feature supplemental steel hooks for bond strengthening along the longitudinal bars. The

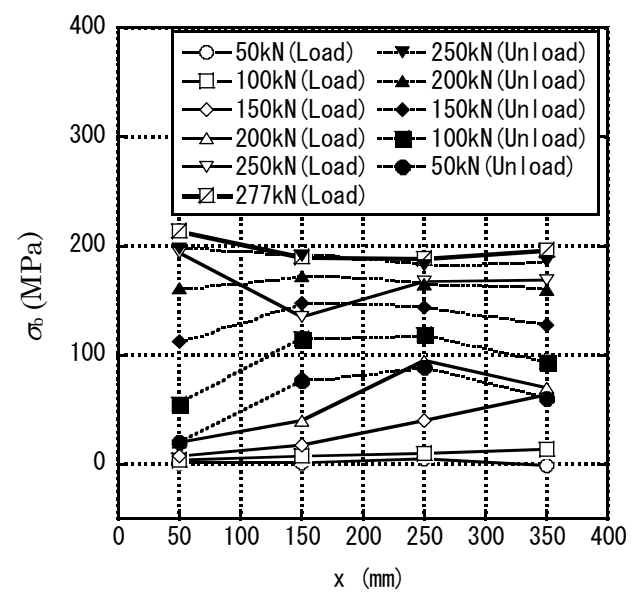

(b) Specimen No. 3

Fig. 12 Distributions of bond strengthening hook stresses. 


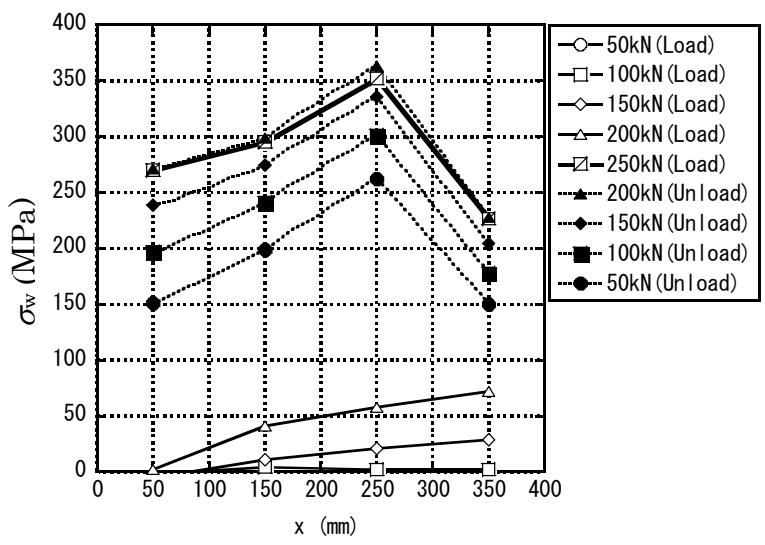

(a) Specimen No. 2

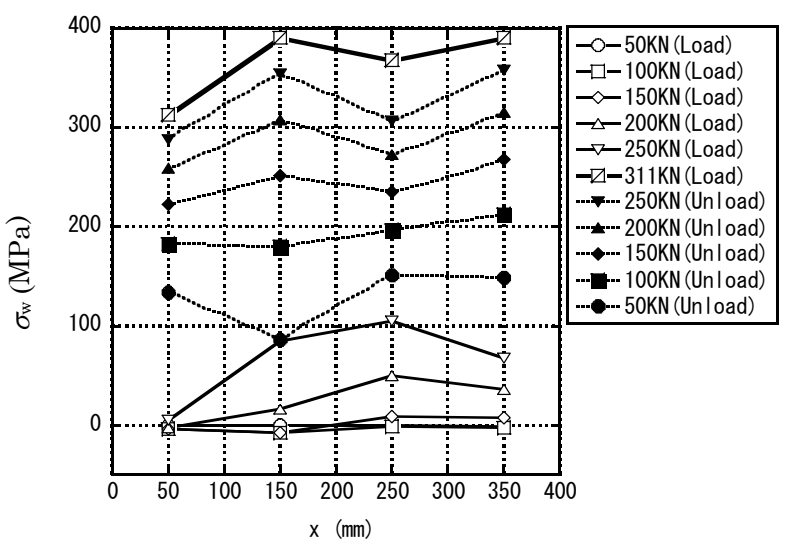

(b) Specimen No. 5

Fig. 13 Distributions of stirup stresses.

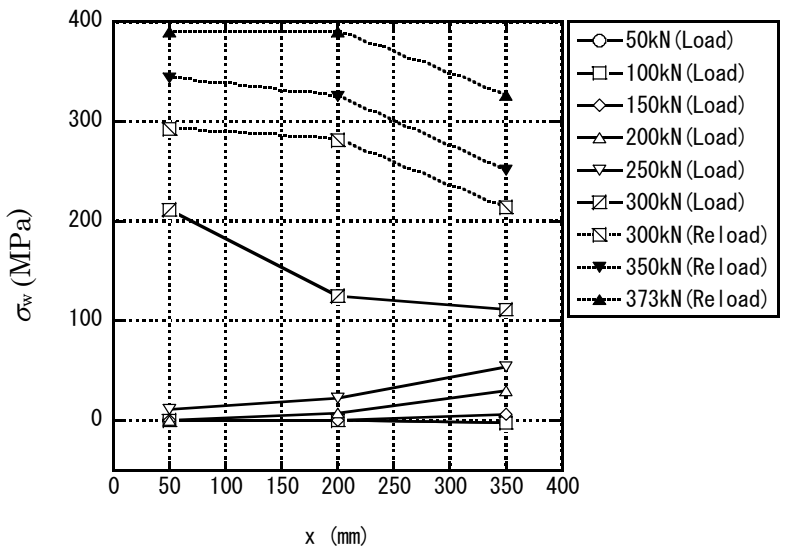

(a) Specimen No. 10: At span that failed first

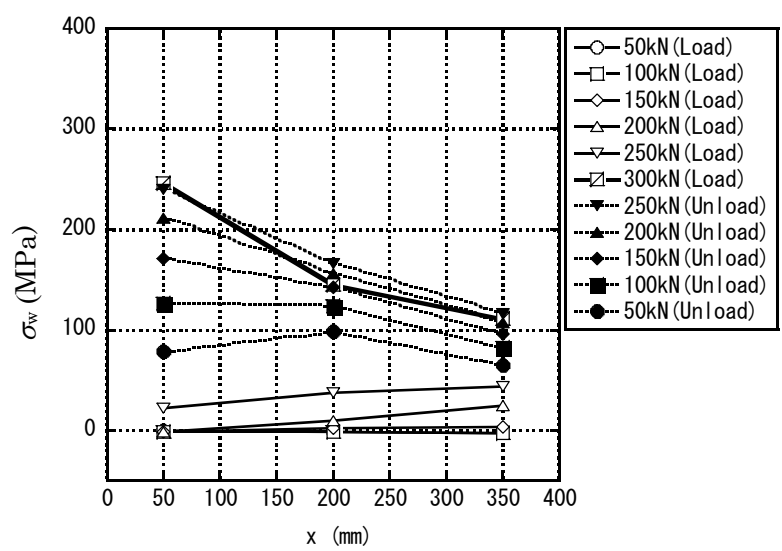

(b) Specimen No. 10: At span that failed second

Fig. 14 Distributions of internal tie stresses.

following remarks are made based on the test results obtained for ten RC beam specimens.

(1) The supplemental hooks acted as effective bond strengthening reinforcements. The effectiveness of the bond strengthening hooks was equivalent to that of stirrups and internal ties with respect to the ratio of net concrete width to total diameter of the longitudinal bars $b_{\mathrm{si}}$, total cross sectional area ratio of the hooks, stirrups, and ties $p_{\mathrm{w}}+p_{\text {be, }}$, and the ratio of the number of anchorages of the stirrups and the hooks to the number of longitudinal bars $\left(N_{\mathrm{w}}+\right.$ $N_{\text {be }}$ )/ $N_{1}$. The modified equations proposed in the previous study rationally estimate the bond strengths of the specimens in these tests under conditions of $b_{\mathrm{si}}=1.6$ to $3.4, p_{\mathrm{w}}+p_{\mathrm{be}}=0.36$ to $0.84 \%,\left(N_{\mathrm{w}}+N_{\text {be }}\right) / N_{1}=0.8 \sim 1.3$, and $f_{\mathrm{c}}^{\prime}=21$ to 29 $\mathrm{MPa}$.

(2) Safe estimates of bond strengths can be given when overlapping of the stress transmitting zones, whose diameter is 15 times the hook diameter (15 $\left.d_{\mathrm{bb}}\right)$, is considered. The influence of overlapping is represented by effective number of hooks $N_{\text {be }}$.

(3) The hooks made of mild steels acted as bond strengthening reinforcements. On the other hand, high-strength steels are preferable for stirrups and internal ties since the shear reinforcements made of mild steel yielded in these tests.

(4) From the viewpoint of bar arranging work, hooks are more advantageous than internal ties for the purpose of bond strengthening.

(5) The strength of RC beams was improved by the bond strengthening hooks. The hooks resulted in strengthening effectiveness equivalent to that of stirrups and internal ties.

\section{Acknowledgement}

Neturen Corporation is acknowledged for graciously providing the steel materials used in this study.

\section{Appendix: Calculations of bond stresses and slips}

The average bond stress $\tau$ is simply calculated by Eq. (A1) since the bars remained elastic: 


$$
\tau=\sum_{i}^{N \mathrm{sg}} \quad d_{\mathrm{b}} E_{\mathrm{s}} \varepsilon_{1, \mathrm{i}} / 4 /\left(400 \mathrm{~mm}-3 s_{\mathrm{g}}\right) / N_{\mathrm{sg}}
$$

where

$E_{\mathrm{s}} \quad=$ elastic modulus of longitudinal bar;

$N_{\mathrm{sg}}=$ number of longitudinal bars to which strain gauges are applied;

$=2$ for specimens No. 1, 2, 3, 4, 5, and 6; 3 for specimens No. 7, 8, 9, and 10;

$s_{\mathrm{g}} \quad=$ length of coating of strain gauge $=25 \mathrm{~mm} ;$

$d_{\mathrm{b}} \quad=$ diameter of longitudinal bar; and

$\varepsilon_{1, \mathrm{i}} \quad=$ strain measured by first strain gauge (at notch) of i-th bar.

Local bond stresses and slips shown in Fig. 10 are derived from Eqs. (A2) to (A9).

$$
\begin{aligned}
& \tau(x=362.5 \mathrm{~mm})=d_{\mathrm{b}} E_{\mathrm{s}}\left(\varepsilon_{1}-\varepsilon_{2}\right) / 4 /\left(75 \mathrm{~mm}-s_{\mathrm{g}}\right) \\
& \tau(x=275 \mathrm{~mm})=d_{\mathrm{b}} E_{\mathrm{s}}\left(\varepsilon_{2}-\varepsilon_{3}\right) / 4 /\left(100 \mathrm{~mm}-s_{\mathrm{g}}\right) \\
& \tau(x=175 \mathrm{~mm})=d_{\mathrm{b}} E_{\mathrm{s}}\left(\varepsilon_{3}-\varepsilon_{4}\right) / 4 /\left(100 \mathrm{~mm}-s_{\mathrm{g}}\right) \\
& \tau(x=62.5 \mathrm{~mm})=d_{\mathrm{b}} E_{\mathrm{s}} \varepsilon_{4} / 4 /\left(125 \mathrm{~mm}-s_{\mathrm{g}} / 2\right) \\
& S(x=362.5 \mathrm{~mm})=\left\{\varepsilon_{1}\left(s_{\mathrm{g}} / 2+12.5 \mathrm{~mm}\right)+\left(\varepsilon_{1}+\varepsilon_{2}\right)\right. \\
& \left.\left(75 \mathrm{~mm}-12.5 \mathrm{~mm}-S_{\mathrm{g}}\right) / 2+\varepsilon_{2} S_{\mathrm{g}} / 2\right\}+S(x=275 \mathrm{~mm}) \\
& S(x=275 \mathrm{~mm})=\left\{\varepsilon_{2} S_{\mathrm{g}} / 2+\left(\varepsilon_{2}+\varepsilon_{3}\right)\left(100 \mathrm{~mm}-S_{\mathrm{g}}\right) / 2\right. \\
& \left.+\varepsilon_{3} S_{\mathrm{g}} / 2\right\}+S(x=175 \mathrm{~mm}) \\
& S(x=175 \mathrm{~mm})=\left\{\varepsilon_{3} s_{\mathrm{g}} / 2+\left(\varepsilon_{3}+\varepsilon_{4}\right)\left(100 \mathrm{~mm}-S_{\mathrm{g}}\right) / 2\right. \\
& \left.+\varepsilon_{4} S_{\mathrm{g}} / 2\right\}+S(x=62.5 \mathrm{~mm}) \\
& S(x=62.5 \mathrm{~mm})=\varepsilon_{4}\left\{s_{\mathrm{g}} / 2+\left(125 \mathrm{~mm}-s_{\mathrm{g}} / 2\right) / 2\right\}+S_{\mathrm{f}}(\text { A } 9)
\end{aligned}
$$

\section{References}

AIJ (1986). Recommendation for Detailing and Placing of Concrete Reinforcement. AIJ, 13-17.
AIJ (1999). Design Guidelines for Earthquake Resistant Reinforced Concrete Buildings Based on Inelastic Displacement Concept. Architectural Institute of Japan, 138-192.

CEB-FIP (1978). Model Code for Concrete Structures. CEB-FIP International Recommendations, 3rd edition, Comité Euro-International du Béton, Paris, 155-160.

Fujii, S., Morita, S., Goto, S., Konishi, T. and Yoshimi, K. (1981). "Evaluation of bond splitting strength." Annu. Rep. Architectural Institute of Japan, Kinki Branch, 197-204. (in Japanese)

Hosokawa, M., Sato, Y., Nagatomo, K. and Nakamura, Y. (2003). "Reinforcement for RC columns with ultra-high-strength spiral and hook-shaped bars." Proceedings of Japan Concrete Institute, 25(2), 865-870. (in Japanese)

Nagatomo, K., Kim, K., Sato, Y. and Kamitani, K. (2003) "Reinforcement for RC beams with ultra-high-strength spiral and hook-shaped bars." Proceedings of Japan Concrete Institute, 25(2), 859-864. (in Japanese)

Sato, Y., Nagatomo, K. and Nakamura, Y. (2003). "Bond-Strengthening Hooks for RC Members with $1300 \mathrm{MPa}-\mathrm{Class}$ Shear-Reinforcing Spirals." Journal of Asian Architecture and Building Engineering, 2(2), 7-14.

Sato, Y., Nagatomo, K. and Nakamura, Y. (2006). "Bond-Strengthening Hooks for RC Members with $1300 \mathrm{MPa}-\mathrm{Class}$ Shear-Reinforcing Spirals Part II Shear Strength Estimation Based on the BCJ-C1166 Guideline." Journal of Asian Architecture and Building Engineering, 5(2), 317-324.

Tanaka, M., Nagatomo, K., Sato, Y. and Kaku, T. (2004). "Bond Behavior of Main Bars in Shear Spans of RC Beams with Hooks and Ultra-High-Strength Spirals." Proceedings of Japan Concrete Institute, 26(2), 829-834. (in Japanese) 